\title{
Implementation of a complexity classification system for inpatient rehabilitation facilities for financing purposes - comparing scales CM Borges*1, F Candoso $^{1}$, HL Ferreira ${ }^{1}$, DS Nogueira1 ${ }^{1}$, A Pereira ${ }^{2}$ and E Reis ${ }^{3}$
}

\author{
Address: ${ }^{1}$ UOFC, Administração Central do Sistema de Saúde, Lisboa, Portugal, ${ }^{2}$ Centro de Medicina de Reabilitação da Região Centro - Rovisco \\ Pais, Tocha, Portugal and ${ }^{3}$ GIESTA, Instituto Superior das Ciências do Trabalho e da Empresa, Lisboa, Portugal \\ * Corresponding author
}

from 25th Patient Classification Systems International (PCSI) Working Conference

Fukuoka, Japan. II-I4 November 2009

Published: 5 November 2009

BMC Health Services Research 2009, 9(Suppl I):A3 doi:I0.1186/1472-6963-9-SI-A3

This abstract is available from: http://www.biomedcentral.com/I472-6963/9/SI/A3

(C) 2009 Borges et al; licensee BioMed Central Ltd.

\section{Introduction}

In Portugal, there is no formal casemix inpatient rehabilitation classification system. The budget for inpatient rehabilitation facilities within the Portuguese NHS is calculated on a per diem basis, with no relation to the diagnosis and the complexity of the patients treated. However, there is an ongoing pilot project where inpatient episodes are classified according to pathology (using ICD 9 CM), functional limitation group, and motor and cognitive functional independency (using the Functional Independence Measure). In a country where there is no systemized information on the complexity of treated rehabilitation inpatients, such a classification may give important information about the treated patients, enabling more adequate care management and resource utilization.

In addition, the aim of this pilot project is to create a specific rehabilitation grouper, where each group has a different price indexed to its complexity. And, as far as rehabilitation care is concerned, it is clear that most of the instruments measuring disability do not accurately reflect the patients' overall clinical conditions. Measuring complexity, especially for financing proposes, is a controversial issue where the use of one instrument instead of another depends on the goal of the financing system. Therefore, the authors compared three different instruments concerning patient classification in rehabilitation inpatient facilities.

\section{Methods}

The aims of this study are to review disability measuring instruments, apply them to a stroke-rehabilitation inpatients sample, and then study the results. The objective is to identify if there is a concordance between the different ways of measuring disability. In the ongoing classification project, inpatient episodes throughout some NHS rehabilitation facilities have been classified retrospectively, and a database of about 1000 episodes, with nearly 400 stroke inpatient episodes, has been created. Also retrospectively, and for the present study, the ICF qualifiers and the Barthel Index were applied to the stroke-rehabilitation inpatients sample of this database. In order to compare final classifications, statistical analysis was carried out to observe the concordance between the instruments.

\section{Results}

In its final results, the study suggests that differences between scales reside mainly in what dimensions they measure. However, if we establish cut points between the disability severity levels in each instrument, and compare them as global or partial single measures, there is a significant concordance between the scales used.

\section{Conclusion}

Both the level of disability in rehabilitation, and the burden of care it implies, have to be integrated into any financing system for inpatient rehabilitation facilities. Each instrument measures complexity differently according to the evaluated dimensions. However, one may or may not come across diverse results about the level of 
patient functional dependence when using different ways of measurement. A patient classification system that will sustain a rehabilitation financing system does not have to integrate all possible dimensions (as it must do for clinical purposes), but it must give an accurate measurement based on complexity and functional dependence. Deciding on what kind of measuring instrument to apply depends on our goal in terms of budgeting.

Publish with Bio Med Central and every scientist can read your work free of charge

"BioMed Central will be the most significant development for disseminating the results of biomedical research in our lifetime. " Sir Paul Nurse, Cancer Research UK

Your research papers will be:

- available free of charge to the entire biomedical community

- peer reviewed and published immediately upon acceptance

- cited in PubMed and archived on PubMed Central

- yours - you keep the copyright

Submit your manuscript here:

http://www.biomedcentral.com/info/publishing_adv.asp 